\title{
A cadeia produtiva da tilápia no oeste do Paraná: uma análise sobre a formação de um arranjo produtivo local
}

\author{
Aldi Feiden \\ Universidade Estadual do Oeste do Paraná \\ Manoel João Ramos \\ Universidade Estadual do Oeste do Paraná \\ Antonio Carlos Chidichima \\ Universidade Estadual do Oeste do Paraná \\ Carla Maria Schmidt \\ Universidade Estadual do Oeste do Paraná \\ Mônica Lady Fiorese \\ Fundação Universidade Regional de Blumenau \\ Anderson Coldebella \\ Universidade Estadual do Oeste do Paraná
}

\section{Resumo}

Este estudo apresenta uma caracterização da cadeia de produção de filé de tilápia na região oeste do Paraná, bem como uma análise das relações sociais, em forma de rede, entre os principais atores que compõem esta cadeia produtiva. A questão central do estudo consiste em avaliar a existência de condições objetivas de se formar um Arranjo Produtivo Local para o processamento de pescado na região estudada, dada a dinâmica de relacionamento e as diferenças estruturais entre os frigoríficos de pescado, bem como a estrutura de governança que se apresenta para a coordenação do sistema. Para tanto, utilizou-se a técnica de Análise de Redes Sociais, que consiste em um método sistemático sob a forma de grafos que permite analisar a estrutura e as ligações existentes entre os diversos atores que compõem a cadeia produtiva ou rede social. Os resultados apontam a existência de uma relevante estrutura produtiva e de agentes potenciais para a formação de um Arranjo Produtivo Local. Da mesma forma, aponta para a existência de uma importante rede de relacionamentos e de cooperação entre os principais elos e atores da cadeia de produção. Entretanto, é notória a importância da contribuição e envolvimento das instituições de apoio organizacional e institucional para a construção deste espaço de desenvolvimento social, econômico e regional.

Palavras-Chave: Arranjo Produtivo. Desenvolvimento Regional. Piscicultura. 
A cadeia produtiva da tilápia no oeste do Paraná: uma análise sobre a formação de um arranjo produtivo local

\title{
Tilapia production chain in western Paraná: analysis of a cluster formation
}

\begin{abstract}
This study presents a description of the tilapia fillet production chain in the western region of Paraná, as well as an analysis of the social relations, as a network, among the main actors which make up this productive chain. The central question of the study is to evaluate the existence of objective conditions to form a cluster for fish processing in the region studied, given the relationship dynamics and the structural differences among the fish slaughterhouses, as well as the governance structure presented for the system coordination. For that, the technique of Social Network Analysis which consists of a systematic method in the form of graphs was used, allowing to analyze the structure and connections among the various actors that make up the productive chain or social network. The results indicate the existence of a relevant productive structure and potential agents to form a cluster. Similarly, they indicate the existence of an important network of relationships and cooperation among the main links and actors in the production chain. However, the importance of the contribution and the involvement of institutional support organizations to weave this space for social, economic and regional development is evident.
\end{abstract}

Key words: Cluster. Regional Development. Fish farming

\section{La cadena productiva de la tilapia en Paraná occidental: un análisis de la formación de un clúster}

\section{Resumen}

Este estudio presenta una caracterización de la cadena de producción de filetes de tilapia en la región oeste de Paraná, así como un análisis de las relaciones sociales, en forma de red, entre los principales actores de esta cadena de producción. La pregunta central de eso estudio es evaluar la existencia de condiciones a la formación de un clúster para el procesamiento de pescado en la región estudiada, dada la dinámica de el relacionamiento y las diferencias estructurales entre los mataderos de pescado, así como la estructura de gobierno que se presenta para la coordinación del sistema. Por lo tanto, se utilizó una técnica de Análisis de Redes Sociales, que consiste en un método sistemático en forma de gráficos que permiten analizar la estructura y las conexiones existentes entre los distintos actores de una cadena productiva o red social. Los resultados muestran la existencia de una importante estructura productiva y de agentes potenciales para la formación de un clúster. Asimismo, apuntan la existencia de una importante red de relaciones y de cooperación entre los principales enlaces y actores de la cadena de producción. Sin embargo, es notoria la importancia de la contribución y la participación de las instituciones de apoyo organizacional e institucional para la construcción del espacio de desarrollo social, económico y regional.

Palabras Clave: Clúster. Desarrollo Regional. Piscicultura.

\section{INTRODUÇÃO}

Este estudo tem por objetivo caracterizar a cadeia de produção de filé de tilápia na região oeste do Paraná, bem como analisar as relações sociais, em forma de rede, entre os principais elos e atores. Esta cadeia produtiva é composta por sete elos principais, dentre os quais se destacam: 1) fazendas aquícolas de produção de 
alevinos e de engorda de peixes; 2) indústrias de ração e premix; 3) empresas de equipamentos para a aquicultura e processamento do pescado; 4) frigoríficos de abate e processamento de peixes; 5) cooperativas e associações de produtores; 6) setores de gestão e organização (instituições de ensino, apoio, pesquisa e extensão) e; 7) instituições de crédito e fomento. $O$ interesse em analisar o relacionamento social em rede consiste em mensurar e compreender as relações de poder, as interações e a participação dos agentes, bem como, a importância destes para o desenvolvimento e formação de um possível Arranjo Produtivo Local - APL.

Neste aspecto, para a formação do APL, são considerados alguns critérios importantes, como a) dinâmica de relacionamento entre os agentes da cadeia produtiva; b) diferenças e semelhanças tecnológicas e estruturais entre os frigoríficos; c) formas de certificação e inspeção sanitária; d) existência de aglomeração regional de empresas em torno de um produto específico (filé de tilápia); e) presença de forte estrutura de apoio, ocupando o mesmo espaço geográfico (região oeste do Paraná); e f) estrutura de governança com capacidade para coordenar as ações de interrelação entre os agentes produtivos. Mediante a análise destes critérios, este estudo pretende responder a seguinte questão: existem condições objetivas para a formação de um APL para o processamento de pescado no oeste paranaense?

Para responder essa questão, utilizou-se como técnica de pesquisa a Análise de Redes Sociais - ARS, um método sistemático sob a forma de grafos que permite analisar a estrutura e as ligações existentes entre os atores que compõem uma determinada rede ou cadeia produção (TOMAEL e MARTELETO, 2013).

$O$ interesse científico em compreender como diferentes atores interagem configurando redes sociais vem sendo ampliado cada vez mais, já que isto permite uma análise de fenômenos singulares, dentre os quais, pode-se destacar a influência das posições sociais dos indivíduos nas redes em relação à formação e mobilização de recursos, assim como no fluxo de informação (RIBEIRO e BASTOS, 2011).

A busca por uma resposta se justifica pelo fato de analisar uma atividade produtiva que vem se destacando na região, além de desempenhar um papel econômico e social de grande importância ao propiciar a geração de emprego e renda. Porém, mesmo diante de um cenário promissor, existem muitos gargalos na cadeia produtiva que podem ser avaliados como oportunidades, principalmente, para a organização do setor e estruturação de um arranjo produtivo em que se possa explorar melhor as vantagens típicas das economias de aglomeração.

Dessa forma, compreender a estrutura da cadeia produtiva e as relações entre seus agentes, bem como a estrutura de governança que se apresenta para a coordenação do sistema, pode contribuir para facilitar um possível processo de formação de um APL do processamento de pescado na região oeste paranaense.

\section{EMBASAMENTO TEÓRICO}

Estudos acerca das aglomerações empresariais vêm adquirindo, cada vez mais, notória representatividade para a análise do desempenho econômico regional ao apontar evidências de externalidades positivas, ou seja, vantagens competitivas oriundas das ações coletivas praticadas entre os agentes de um determinado segmento econômico ao se relacionarem entre si. 
Conforme ressalta Lemos (1999), tendências apontam para a organização das empresas em redes gerando um fortalecimento e enriquecimento do ambiente territorial por meio de oportunidades que oferecem troca de informações, transmissão de conhecimento e mobilidade de competências.

Nesse aspecto, Almeida Filho (2005) salienta que a organização de empresas em rede pode ser considerada como uma representação poderosa de sistemas complexos. Grandori e Soda (1995) acrescentam que algumas organizações são formalizadas por meio de contratos, enquanto outras, podem ser ligadas apenas por relações sociais, ao manterem interações informais e puramente sociais, dedicando-se à troca de informações e recursos, sem o uso de qualquer contrato formal. Entretanto, apesar dessa informalidade e aparente simplicidade, muito se argumenta sobre a importância dos relacionamentos sociais em redes para a sobrevivência de organizações de todos os tipos.

Conforme destacam Knoke e Yang (2008), podem ser considerados como agentes ou atores de uma rede, pessoas individuais ou organizações (formais ou informais), sendo que a relação entre eles, geralmente, pode ser definida como um tipo específico de contato, conexão ou laço existente.

Para Lazzarini (2008), a definição de rede pode ser entendida como um conjunto de indivíduos ou organizações que interagem entre si por meio de relacionamentos diversos, sendo que a composição dessa rede se dá por nós e laços. Os nós representam os atores (indivíduos, organizações) e os laços, as relações que existem entre eles.

Sobre as estruturas de relacionamento nas redes, Granovetter (1973) apresenta os conceitos de "laços fortes" e "laços fracos", em que a força de um laço pode ser discernida mediante alguns critérios, tais como: quantidade de tempo, intensidade emocional, intimidade e serviços recíprocos que permeiam a relação entre os atores que compõem a rede. Dessa forma, os laços fortes seriam as relações mais próximas e frequentes que, geralmente, fazem parte do mesmo círculo social, enquanto que os laços fracos, seriam as relações mais dispersas. Se por um lado, os laços fracos são menos consistentes, por outro, possibilitam o estabelecimento de ligações com contatos mais longínquos do que aqueles que os laços fortes conseguem alcançar. Para Granovetter (1973), os laços fortes podem ser inibidores ou pouco propensos a sustentar as atividades empreendedoras dos indivíduos, visto que não são capazes de dotá-los de informações muito diferentes daquelas que já circulam em seu ambiente de relacionamento. Por sua vez, os laços fracos, ao conectarem o indivíduo com ambientes diferentes e mais distantes, permitem maior circulação e difusão de diferentes tipos de informação, o que é relevante no mundo dos negócios. O autor também destaca, nesse contexto, o papel dos empreendedores como articuladores de redes.

Nesse aspecto, Tomael e Marteleto (2006) salientam que o que movimenta e configura uma rede social é o compartilhamento de informações, sendo assim, a disposição em compartilhar e a troca eficiente de informações entre os atores de uma rede asseguram ganhos, haja vista que cada participante pode melhorar o seu desempenho, valendo-se das informações às quais passa a ter acesso.

Lemos (1999, p. 135) afirma que a capacidade de inovação pode ser influenciada pelos diversos formatos organizacionais em redes, tais como: alianças estratégicas, arranjos produtivos locais, clusters e distritos industriais, os quais possibilitam a interação entre diferentes agentes. 
Nesse sentido, considerando a ampliação dos conceitos de redes de empresas, é importante pensar a rede sob o formato de APL, ou seja, a rede baseada na concentração geográfica de integrantes de uma mesma cadeia produtiva. Ela sustenta-se na ideia de que, organizados em forma de redes, os agentes ou atores da cadeia podem explorar melhor as vantagens típicas das economias de aglomeração, como compartilhamento de infraestrutura, treinamento conjunto de mão de obra, compras conjuntas de -prima e insumos, entre outros benefícios. Isso é alcançado por intermédio do estabelecimento de laços mútuos de solidariedade e cooperação, que Ihes permitem compartilhar algum tipo de recurso e aproveitar as sinergias existentes no local (Rosa, 2004).

A principal referência ao se tratar de APL no Brasil é a Rede de Pesquisa em Sistemas Produtivos e Inovativos Locais - RedeSist desenvolvida pela Universidade Federal do Rio de Janeiro - UFRJ com o apoio e a participação de outras universidades e de outros institutos de pesquisa. A RedeSist (2003) define APL como aglomeração de empresas em que existam agentes econômicos, políticos e sociais em um mesmo território, tendo como base uma economia e foco específico, com vínculos de trabalho e negócios que se assemelham, envolvendo a participação e interação de várias empresas, desde a produção de serviços e matéria prima até a comercialização do produto, sendo representada por algum sistema de governança, como associações, entre outras.

Para Graça (2007), a inovação tecnológica é decorrente da conjuntura de concorrência de um mercado, destacando a importância das estruturas de governança na geração de capacidade de inovação dos APLs. Nesse sentido, as estruturas de governança podem ser compreendidas como "[...] a capacidade de comando ou coordenação que certos agentes ou instituições exercem sobre as inter-relações produtivas, comerciais, tecnológicas entre outras, influenciando de forma decisiva no desenvolvimento de um sistema ou arranjo produtivo local". Assim, "[...] a governança é um dos aspectos mais complexos dentre os que caracterizam a dimensão espacial das atividades produtivas e inovadoras" (SUZIGAN et al., 2007, p. 1). Essa complexidade é resultante do difícil equilíbrio que a forma de governança mantém entre cooperação e competição no âmbito do APL, bem como da grandeza de fatores que condicionam a governança.

As estruturas de governança surgem nos APLs a partir do momento em que os agentes buscam ir além do simples aproveitamento das vantagens competitivas decorrentes das economias de aglomeração e procuram desenvolver ações coletivas ou conjuntas, estreitando suas interdependências em busca da eficiência, desenvolvendo parcerias nas esferas pública, privada e educacional (SUZIGAN et al., 2007).

Dessa forma, a capacidade de comandar as relações entre as empresas e a governança da atividade produtiva deve ser considerada como fator de extrema importância na constituição de APLs. Sendo assim, Lastres e Cassiolato (2003) asseveram que o conceito de governança, de modo genérico, associa-se às diversas formas pelas quais agentes e organizações (públicas e privadas) gerenciam seus problemas comuns, acomodando interesses conflitantes ou diferenciados e realizando ações cooperativas. Os autores destacam ainda que, no caso específico dos APLs, a governança diz respeito às distintas formas de coordenação, intervenção e participação nos processos de decisão e dos diferentes agentes (Estado, em seus vários níveis, empresas, cidadãos e trabalhadores, organizações 
A cadeia produtiva da tilápia no oeste do Paraná: uma análise sobre a formação de um arranjo produtivo local

não governamentais etc.); e também em relação às diversas atividades que envolvem a organização dos fluxos de produção, assim como o processo de geração, disseminação e uso de conhecimentos.

De forma complementar, Lastres e Cassiolato (2003) ressaltam que existem duas principais formas de governança em sistemas produtivos locais, sendo uma a forma de governança hierárquica, em que a autoridade é internalizada dentro de grandes empresas, com real ou potencial capacidade de coordenar as relações econômicas e tecnológicas no âmbito local, e a outra, a governança na forma de redes, que caracteriza-se pela existência de aglomerações de micro, pequenas e médias empresas, sem a presença de grandes empresas localmente instaladas exercendo o papel de coordenação das atividades econômicas e tecnológicas.

A governança hierárquica surge geralmente a partir de uma série de situações em que alguma forma de coordenação e liderança local condiciona e induz o surgimento da aglomeração de empresas, enquanto que a governança na forma de redes é caracterizada pela forte intensidade de relações entre um amplo número de agentes, onde nenhum deles é dominante. Assim, conforme os agentes se relacionam em determinado contexto, regidos por mecanismos de coordenação e controle, formam-se estruturas de governança. A estrutura de governança é constituída pelo conjunto de atores envolvidos na atividade e por suas ações de coordenação, especialmente quanto à identificação de problemas conjuntos, proposições de soluções e elaboração de estratégias a serem implementadas para o sucesso da atividade (CAMPOS e CALLEFI, 2009).

Existem diversos atributos, critérios e objetivos a serem observados e considerados quando se busca avaliar as possibilidades de formação de um APL.

\section{Quadro 1. Critérios e objetivos na formação de um Arranjo Produtivo Local}

\begin{tabular}{|c|c|c|}
\hline CRITÉRIOS & OBJETIVOS & FONTE \\
\hline $\begin{array}{c}\text { Formação do } \\
\text { Conhecimento Local }\end{array}$ & $\begin{array}{l}\text { Identificar a presença de instituições de ensino, pesquisa e } \\
\text { extensão com potencial para agir como propulsores na } \\
\text { formação do APL, podendo estimular ações tecnológicas, } \\
\text { institucionais e organizacionais entre os agentes. }\end{array}$ & $\begin{array}{l}\text { Cantner e Graf } \\
\text { (2011) }\end{array}$ \\
\hline $\begin{array}{l}\text { Economias de } \\
\text { Aglomeração }\end{array}$ & $\begin{array}{l}\text { Avaliar as possibilidades de melhor explorar as vantagens } \\
\text { típicas das economias de aglomeração, como } \\
\text { compartilhamento de infraestrutura, treinamento conjunto } \\
\text { de mão de obra, compras conjuntas realizadas entre os } \\
\text { agentes da cadeia de produção, entre outras vantagens. }\end{array}$ & $\begin{array}{l}\text { Rosa (2004); } \\
\text { Suzigan (2007). }\end{array}$ \\
\hline $\begin{array}{l}\text { Concentração } \\
\text { Geográfica }\end{array}$ & $\begin{array}{l}\text { Verificar a aglomeração de empresas em que existam } \\
\text { agentes econômicos, políticos e sociais em um mesmo } \\
\text { território, voltados a uma atividade relacionada a um } \\
\text { produto final comum. }\end{array}$ & RedeSist (2003) \\
\hline $\begin{array}{l}\text { Compartilhamento e } \\
\text { Troca de Informações }\end{array}$ & $\begin{array}{l}\text { Mensurar a disposição para compartilhar e trocar de forma } \\
\text { eficiente informações entre os atores, visando a melhoria } \\
\text { do desempenho comum. }\end{array}$ & $\begin{array}{l}\text { Tomael e Marteleto } \\
\text { (2006) }\end{array}$ \\
\hline $\begin{array}{l}\text { Intensidade de } \\
\text { relacionamento entre } \\
\text { os agentes }\end{array}$ & $\begin{array}{l}\text { Identificar o grau de participação e interação de agentes de } \\
\text { várias empresas, desde a obtenção da matéria-prima e } \\
\text { prestação de serviços até a comercialização do produto } \\
\text { final. }\end{array}$ & $\begin{array}{l}\text { Grandori e Soda } \\
\text { (1995); } \\
\text { Lazarini (2008); } \\
\text { RedeSist (2003). }\end{array}$ \\
\hline
\end{tabular}


(conclusão)

\begin{tabular}{|c|c|c|c|}
\hline \multirow{4}{*}{ 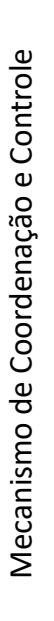 } & $\begin{array}{l}\text { Sistema de } \\
\text { Governança }\end{array}$ & $\begin{array}{l}\text { Verificar a existência de um sistema de governança, como } \\
\text { associações ou outras instituições de apoio com } \\
\text { capacidade de comando ou coordenação sobre as } \\
\text { interrelações produtivas, comerciais e tecnológicas. }\end{array}$ & $\begin{array}{l}\text { RedeSist (2003); } \\
\text { Graça (2007); } \\
\text { Suzigan et al. } \\
\text { (2007); Lastres e } \\
\text { Cassiolato (2003). }\end{array}$ \\
\hline & $\begin{array}{c}\text { Grau de } \\
\text { Centralidade }\end{array}$ & $\begin{array}{l}\text { Identificar a quantidade de interações existentes entre os } \\
\text { atores e demonstrar a capacidade de diversificação dos } \\
\text { relacionamentos; }\end{array}$ & $\begin{array}{l}\text { Oliveira et al., } \\
\text { (2014); } \\
\text { Mccarty (2002). }\end{array}$ \\
\hline & $\begin{array}{c}\text { Grau de } \\
\text { Intermediação }\end{array}$ & $\begin{array}{l}\text { Avaliar a quantidade de vezes que um agente é utilizado } \\
\text { por outro como caminho para alcançar um terceiro, } \\
\text { indicando a potencialidade para controlar o fluxo de } \\
\text { informação e funcionar como ponte ente os demais } \\
\text { agentes. }\end{array}$ & $\begin{array}{l}\text { Oliveira et al., } \\
\text { (2014); Hanneman e } \\
\text { Riddle (2005). }\end{array}$ \\
\hline & $\begin{array}{c}\text { Grau de } \\
\text { proximidade }\end{array}$ & $\begin{array}{l}\text { Identificar a capacidade que tem um determinado ator } \\
\text { para alcançar os demais elos da rede. }\end{array}$ & $\begin{array}{l}\text { Oliveira et al., } \\
\text { (2014) }\end{array}$ \\
\hline
\end{tabular}

O quadro 1 destaca, resumidamente, alguns desses critérios, relevantes no processo de análise e investigação do ambiente de relacionamento e interação dos agentes, bem como a formação de uma estrutura de governança para o arranjo produtivo local.

Dessa forma, avalia-se que o sucesso de uma atividade pode advir de possíveis vantagens competitivas originárias da organização em APLs entre micro e pequenas empresas. Entre as principais vantagens, Amato Neto (2000, p. 42) destaca as seguintes:

[...] combinar competências e utilizar know-how já desenvolvido por outras empresas, dividir custos de pesquisas tecnológicas, dividir riscos e custos ao explorar novas oportunidades e fazer experiências em conjunto, aumentar a pressão sobre o mercado, e consequentemente a força competitiva, compartilhar recursos, reduzindo ou eliminando a subutilização dos mesmos e fortalecer-se para enfrentar o mercado internacional.

Nesse contexto, o referencial teórico apresentado serve de embasamento para facilitar a mensuração acerca dos principais critérios e objetivos a serem almejados no processo de análise para formação de um possível APL da produção de filé de tilápia na região oeste do Paraná, com vistas à compreensão das formas de relacionamento que ocorrem na cadeia produtiva e, assim, possibilitar a avaliação de potenciais estruturas de governança com perfil para o gerenciamento de problemas comuns e interesses conflitantes ou diferenciados, bem como realizar ações cooperativas que proporcionem benefícios coletivos e resulte em uma importante estratégia de competitividade neste setor da economia local e regional.

\section{PROCEDIMENTOS METODOLÓGICOS}

Este estudo caracteriza-se como uma pesquisa exploratória e descritiva, conforme destaca (Gil 2002), com vistas ao levantamento de dados no intuito de caracterizar os principais elos inseridos na cadeia produtiva da tilapicultura da região oeste paranaense, bem como a interação existente entre os principais atores. Para tanto, foram efetuadas entrevistas, visitas técnicas e aplicação de questionários semiestruturados junto aos agentes-chave da cadeia analisada. 
A cadeia produtiva da tilápia no oeste do Paraná: uma análise sobre a formação de um arranjo produtivo local

A pesquisa foi realizada entre os meses de janeiro a dezembro de 2016. Nesse período, além dos contatos realizados por meio de visitas técnicas com os principais atores da cadeia, realizou-se, da mesma forma, um levantamento de informações junto a órgãos públicos, como prefeituras e secretarias municipais, órgãos estaduais, como Secretaria de Estado da Agricultura e do Abastecimento $\mathrm{SEAB}$, além de contatos com representantes comerciais, instituições de crédito, ensino pesquisa e extensão.

Essa etapa, com vistas ao levantamento de dados acerca dos elos existentes possibilitou identificar sete setores ligados à cadeia produtiva, localizados na região oeste do Paraná. Esses setores foram organizados conforme a metodologia PENSA de estudos de sistemas agroindustriais, abrangendo desde a obtenção da matériaprima e insumos até a comercialização do produto final. A metodologia organiza as atividades em quatro segmentos, que são apresentados nos resultados desta pesquisa.

As visitas técnicas e entrevistas realizadas nas unidades de produção foram determinantes para identificar a atuação dos principais elos envolvidos na cadeia produtiva. Foram considerados, como objeto de pesquisa e empresas focais, apenas os estabelecimentos de abate e processamento de pescado em atividade na região, que possuíam algum tipo de regulação por parte do governo, ou seja, atuavam sob as chancelas do Sistema de Inspeção Municipal - SIM, Sistema de Inspeção Estadual do Paraná - SIP, Sistema Brasileiro de Inspeção de Produtos de Origem Animal SISBI/POA ou Sistema de Inspeção Federal - SIF. Mediante a este filtro, foram identificadas a presença de 24 unidades frigoríficas. Todos estes estabelecimentos industriais foram visitados pelos pesquisadores para aplicação dos questionários e entrevista aos proprietários e/ou responsáveis.

Com base nos questionários aplicados, foi efetuada a ARS observando o emprego de fundamentos metodológicos, como a estatística e a análise de grafos. Dessa forma, as análises partem de pressupostos matemáticos para derivar afirmações teóricas, limitado ao escopo de análise aos grafos e as derivações de análise por meio de sociogramas. De uma maneira bem simples, os grafos podem ser entendidos como um conjunto de pontos, convencionalmente denominados de vértices ou nodos, conectados por linhas chamadas de arcos ou arestas.

No método proposto pela ARS são produzidas algumas formas de mensuração relativas à estrutura da rede, como densidade e centralização e proximidade, sendo que a densidade da rede se refere ao número total de laços em uma rede em relação ao número de possibilidades totais de laços que poderiam ser formados. Por outro lado, a centralização da rede está relacionada com a distribuição de poder ou controle na rede enquanto que a proximidade busca identificar a capacidade que tem um determinado ator para alcançar os demais elos da rede (KIM et al., 2011; Oliveira et al., 2014).

Diferentemente da centralidade, a análise de densidade não está focada no indivíduo, mas, sim, na estrutura que se forma na rede, ou seja, a densidade busca identificar o quanto uma rede está interligada facilitando o fluxo entre os elos de modo mais igualitário. A densidade é calculada por meio da proporção entre a quantidade de elos existentes pelo total de elos possíveis na estrutura.

Para possibilitar a mensuração das interações existentes na cadeia produtiva, os dados obtidos foram tratados mediante a utilização do software Ucinet $6.627^{\circledR}$, com base nos questionários aplicados juntos aos responsáveis dos frigoríficos. 
Nesse questionário, considerou-se a existência ou não de relações entre os atores, em que as relações variavam de 0 a 1 , sedo que o 0 indica que não há qualquer contato entre os elos, e o 1 indica a existência de contato direto entre os elos da cadeia produtiva.

A partir da aplicação desses questionários e entrevistas realizadas com os responsáveis ou proprietários de frigoríficos de pescado, juntamente com os dados da pesquisa documental, procedeu-se uma análise de conteúdo dos dados, os quais serviram de subsídio para o entendimento sobre as estruturas de governança, bem como auxiliaram na fundamentação qualitativa dos resultados dos indicadores para a formação da rede de inovação em APL e, após essas etapas, procedeu-se a uma triangulação das análises das três fontes de dados (entrevistas, pesquisa documental e questionários) a fim de compor as considerações finais acerca deste estudo.

\section{RESULTADOS E DISCUSSÃO}

Para uma melhor compreensão, os resultados estão apresentados em três seções. Na primeira seção, tem-se a caracterização de cada um dos sete principais elos da cadeia produtiva, identificados em decorrência do estudo aplicado a campo; na segunda seção, apresenta-se uma análise da rede de relacionamentos entre os principais atores da cadeia, obtida a partir da aplicação de questionários e utilização do software Ucinet $6.627^{\circledR}$ e; na terceira seção, analisa-se de forma conjunta, a inserção dos atores na rede, bem como a estrutura de governança que se apresenta para a formação de um possível APL, tendo como base os critérios e objetivos estabelecidos anteriormente.

\section{Caracterização da Cadeia Produtiva}

Nesta seção, caracteriza-se os principais elos da cadeia produtiva, envolvendo um conjunto de etapas, desde a obtenção de matéria-prima e insumos até a comercialização do produto final.

Industrialização de ração e premix

Verificou-se, no decorrer deste estudo, que na região oeste do Paraná, são produzidas e comercializadas várias marcas de ração para peixes, que são distribuídas de diferentes formas, desde a entrega direta pela indústria ao piscicultor, via produção integrada, à aquisição da ração via atacado ou varejo.

Dentre os atores que atuam nesse segmento, foram identificados 14 fornecedores de ração. Destes, seis estão instalados no oeste paranaense, sendo dois no Município de Toledo e uma unidade em cada um dos municípios de Ouro Verde do Oeste, Cascavel, Corbélia e Cafelândia. Também foi identificada a presença de cinco indústrias de aditivos (premix) para rações, sendo duas instaladas no Município de Toledo, duas em Cascavel e uma em Maripá.

O estudo identificou que mais de $42 \%$ dos fornecedores de ração estão localizados na região, podendo destacar a força deste elo para a formação de um APL no setor produtivo da tilápia. De acordo com o Boletim Informativo do setor de alimentação animal, Sindicato Nacional da Indústria de Alimentação Animal Sindirações (2016), no Brasil, o crescimento deste segmento entre os anos de 2015 para 2016 foi de $2,9 \%$, sendo que a produção de rações para o setor de piscicultura 
A cadeia produtiva da tilápia no oeste do Paraná: uma análise sobre a formação de um arranjo produtivo local

cresceu 7,8\%, enquanto que, para suínos e aves, o crescimento foi de 3,0\% no mesmo período. Isso indica que o setor de rações e premix apresenta um grande potencial para a economia regional.

\section{Empresas de equipamentos para piscicultura}

Dentre os elos para a formação do APL da piscicultura, as indústrias de máquinas e equipamentos representam fundamental importância. Estas indústrias fornecem equipamentos para produção, despesca, transporte e processamento de pescado, com inovações e aprimoramento necessários ao setor.

Foram identificadas na pesquisa seis empresas relacionadas à produção e comercialização de máquinas e equipamentos. Destas, duas estão localizadas no Município de Toledo e as demais localizam-se nos municípios de Palotina, Assis Chateaubriand, Cascavel e Marechal Cândido Rondon. Embora essas empresas apresentem capacidade de atendimento ao possível APL, também comercializam equipamentos para a pesca esportiva e profissional, como artefatos, acessórios de camping, entre outros.

Nesse elo, destacam-se as empresas de industrialização e comercialização de aeradores, alimentadores (manuais e automáticos), silos de armazenagem de ração e equipamentos específicos para as indústrias de processamento do pescado, tais como: bancadas, mesas de filetagens, lavadores de mão e botas, esteiras transportadoras, entre outros equipamentos.

As máquinas e equipamentos utilizados para a produção dos peixes nos tanques e para o processamento nos frigoríficos são manufaturados em várias regiões do País. Entretanto, existem diversas indústrias deste segmento instaladas na região estudada, que atendem as indústrias alimentícias e grande parte das demandas dos frigoríficos da região. Esses equipamentos são de fundamental importância para o aumento na produção da tilápia nos tanques de engorda e no setor industrial, proporcionando melhor qualidade e maior produtividade.

Setor de criação de alevinos e engorda de peixes

Como qualquer atividade, a produção de "sementes" é indispensável para o desenvolvimento da cadeia produtiva. No caso da tilapicultura, a regra permanece. O aumento da produção de pescado cultivado, entre outros fatores, está diretamente relacionado à produção de alevinos. Nesse setor, cada vez mais exigente em qualidade e tecnologia de produção, o mercado vem selecionando os produtores e, apesar do aumento na quantidade de alevinos de tilápias comercializados anualmente, a quantidade de produtores de alevinos diminuiu. Entretanto, o grau de intensificação da produção e de formação dos produtores evoluiu de forma expressiva nos últimos anos. De acordo com o Instituto Brasileiro de Geografia e Estatística - IBGE (2014), a produção de alevinos nas 27 unidades federativas do Brasil representou $4 \%$ da movimentação econômica da aquicultura, com mais de $\mathrm{R} \$ 150$ milhões para uma produção nacional de aproximadamente de 800.000 milheiros. Segundo este mesmo estudo, a produção em relação a 2013 apresentou um decréscimo de $2,6 \%$ em relação à quantidade produzida, porém, em relação ao valor gerado, o aumento foi de $20,6 \%$.

Nesse cenário, o Estado do Paraná permanece na liderança da produção com 21,9\% do total produzido no País, com destaque para os municípios de Toledo com 
42.000 milheiros e Palotina, com 40.000 milheiros, colocando estes dois municípios no topo do ranking da produção nacional.

Dados obtidos junto aos órgãos responsáveis, considerando o período de safra de 2014/2015, apresentaram que existem, na região oeste paranaense, 24 estações de produção de alevinos em funcionamento, dentre as quais, oito estão localizadas no Município de Toledo, quatro em Marechal Cândido Rondon, três em Assis Chateaubriand, duas em Nova Aurora e Palotina. Os municípios de Cascavel, Guaíra e Tupãssi contam com uma estação cada, sendo que, neste período, todas as estações juntas produziram 143.000 milheiros de alevinos de tilápia.

Doravante, juntamente com o pacote tecnológico da produção de alevinos, ocorreu o crescimento do setor da engorda de peixes. No início dos anos de 1980, a concentração de produtores estava nos municípios de Toledo, Assis Chateaubriand e Marechal Cândido Rondon. Porém, com a expansão da atividade, outros municípios da região oeste também se destacaram, como o Munícipio de Maripá que, atualmente, é referência na produção estadual.

De acordo com informações da SEAB Paraná, o valor que a atividade da aquicultura agregou aos bens e serviços consumidos no seu processo produtivo no ano de 2014 no Estado, foi de R\$ 425,6 milhões, sendo que deste montante, 47,3\% está concentrado apenas no oeste do Estado. Ainda segundo a SEAB/PR, o cultivo de peixes no Paraná tem maior concentração na região oeste, como fonte de renda de pequenos produtores e a principal espécie produzida é a tilápia (SEAB/PR, 2016).

Dessa forma, a expressividade produtiva e o bom desempenho da região indicam que os setores de criação de alevinos e o de engorda de peixes apresentam um grande potencial para a economia regional.

\section{Setor de abate e processamento do pescado}

A pesquisa realizada junto aos municípios do oeste paranaense identificou 24 estabelecimentos frigoríficos que realizam o abate e processamento de pescado em que a espécie tilápia é a principal matéria-prima. Esses frigoríficos estão instalados em 13 municípios da região, com a maior concentração no Município de Toledo, onde estão instalados seis estabelecimentos.

Ressalta-se que, dos empreendimentos identificados na região, 19 possuem habilitação para abater e processar o pescado seguindo as normas da vigilância sanitária com certificação do SIM/POA, outros dois possuem habilitação sob a chancela do Sisbi/POA e os demais são inspecionados pelo SIF/POA.

Os frigoríficos identificados na pesquisa são classificados como principais agentes potenciais para a formação do APL na região de estudo, com abate e processamento de cerca de 160 toneladas de tilápias/dia, o que corresponde a aproximadamente 54 toneladas de filé, gerando mais de 1.200 empregos diretos nos frigoríficos. Dessa totalidade de estabelecimentos, nove abatem mais de cinco toneladas de pescado/dia e, entre estes, os dois de maior porte atuam no modelo cooperativista e os demais são de propriedades particulares com características de gestão familiar.

É importante destacar que, mesmo tendo apenas um frigorífico instalado, o Município de Nova Aurora se destaca na produção, com processamento de 60 toneladas/dia de pescado. Outro fato relevante consiste na aglomeração dos principais frigoríficos em apenas três municípios: sendo seis em Toledo, três em Cascavel e três em Marechal Candido Rondon, o que implica na criação de um polo 
A cadeia produtiva da tilápia no oeste do Paraná: uma análise sobre a formação de um arranjo produtivo local

regional de produção, conforme se observa na (Figura 1), que também destaca a localização dos demais elos envolvidos na cadeia de produção.

Figura 1. Mapa de localização e concentração dos agentes produtivos da cadeia do pescado no oeste do Paraná

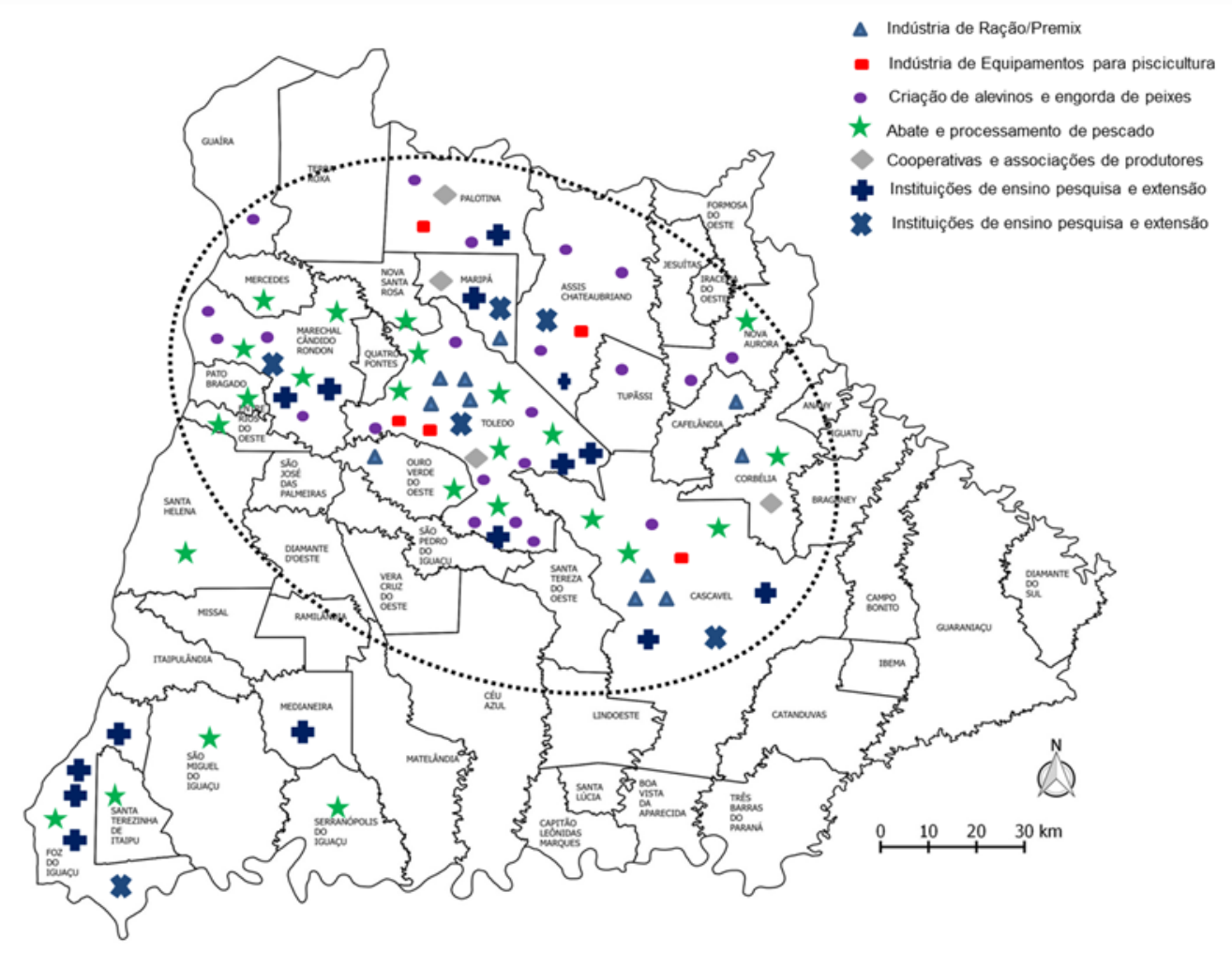

Fonte: Dados da Pesquisa (2016)

Nesse contexto, Storper e Harrison (1991) e Rosa (2004) destacam a importância da dimensão territorial da atividade produtiva e a conformação de aglomerações de empresas e demais atores da cadeia para a estruturação da governança em arranjos produtivos locais, em que a presença concentrada de empresas de um mesmo segmento industrial pode atrair fornecedores e prestadores de serviços, fazendo com que estes desenvolvam intensas interações entre as empresas locais.

Para Cardoso et al. (2014, p. 8) "[...] a noção de território é importante para a atuação em um APL, já que a aglomeração se dá em um determinado espaço físico". Dessa forma, o APL pode compreender, territorialmente, parte de regiões ou municípios, devendo possuir aspectos que identifiquem alguma ação coletiva que proporcione benefícios em comum.

Setor de cooperativas e associações de produtores

No que se refere aos atores envolvidos na tilapicultura, como cooperativas e associações de produtores, estas têm papel fundamental na consolidação da atividade. Nesta pesquisa, foram identificadas duas cooperativas de processamento, sendo uma em Cafelândia e a outra em Toledo. Essas cooperativas atuam com forte presença na região, participando diretamente de todo o processo, 
desde a produção de ração, alevinos, engorda da tilápia, abate e processamento até a comercialização e distribuição dos produtos no mercado.

A força cooperativista aparece em destaque na pesquisa ao expressar capacidade de abate em mais de $50 \%$ da produção dos 24 frigoríficos. Na pesquisa, foi possível identificar intenções de incremento de produção para as duas unidades cooperativistas atuantes no setor, com a pretensão de dobrarem suas produções nos próximos anos. Ademais, existe uma planta em construção de uma terceira cooperativa agroindustrial atuante na região, no segmento de aves, com sede em Palotina, que projeta um abate de 50 toneladas/dia de tilápia para o ano de 2017.

Quanto à participação das associações na atividade produtiva, identificou-se, na pesquisa, que existem duas associações ativas, sendo uma em Maripá e outra em Palotina. As atividades principais dessas associações estão direcionadas ao apoio organizacional, atuando na defesa dos interesses e promoção de eventos coletivos de apoio aos associados, entre outras ações.

\section{Setor de instituições de ensino, pesquisa e extensão}

No que se refere ao apoio na formação de mão de obra especializada para o setor que atende às necessidades de capacitação para atuação na gestão e produção, são várias as instituições de ensino superior que podem dar suporte para esta formação. Dentre as instituições federais, quatro estão em atividade na região oeste paranaense, que são: Universidade Federal da Integração Latino-Americana Unila, Universidade Tecnológica Federal do Paraná - UTFPR, a Universidade Federal do Paraná - UFPR e o Instituto Federal do Paraná - IFPR. No âmbito estadual, a Universidade Estadual do Oeste do Paraná - Unioeste atua com curso de graduação em Engenharia de Pesca e com Mestrado e Doutorado em Recursos Pesqueiros e Engenharia de Pesca e, nesta mesma linha, a UFPR oferece curso de Engenharia em Aquicultura em níveis de graduação e pós-graduação.

Como suporte para outras áreas de formação de profissionais, existem cerca de 30 instituições de ensino privadas que oferecem curso de formação na área de medicina veterinária, engenharia de alimentos, engenharia de produção, engenharia agrícola, farmácia, biologia, recursos humanos, administração, entre outros.

Como apoio e desenvolvimento de pesquisa, dando suporte para a evolução dos processos e melhoria na atividade, a região conta com o Instituto Água Viva, no Município de Toledo, que atua com pesquisa na área de piscicultura e meio ambiente e a Fundação para Desenvolvimento Científico Tecnológico - Fundetec situada em Cascavel, que atende às necessidades regionais com Centros de Incubação Tecnológica, Laboratório de Análise Físico-Química e Microbiológica e Laboratório de Inovação, incluindo espaço para incubação de empresas.

Outros agentes como o Instituto Paranaense de Assistência Técnica e Extensão Rural - Emater apresenta apoio direto aos produtores, promovendo palestras, cursos e assistência técnica. Com aspecto voltado para a formação gerencial no ramo empresarial e do agronegócio, o Serviço de Apoio à Micro e Pequenas Empresas - Sebrae tem forte presença junto a vários elos que são potenciais na formação do APL da tilapicultura na região de estudo, atuando diretamente com cursos e apoio financeiro, formando parcerias com as empresas do setor e, neste mesmo aspecto, apresenta-se o Serviço Nacional de Aprendizagem Rural - Senar que também fomenta a atividade na região. 
A cadeia produtiva da tilápia no oeste do Paraná: uma análise sobre a formação de um arranjo produtivo local

Além desses agentes, destaca-se ainda o Programa Oeste em Desenvolvimento, vinculado ao Parque Tecnológico da Itaipu Binacional (PTI), que vem promovendo ações no sentido de coordenação da cadeia produtiva do peixe, entre outras ações voltadas para outras cadeias de proteína animal, como leite, aves e suínos e também ações voltadas para a logística regional.

Nesse aspecto, conforme pressuposto por Suzigan (1999) e Cassiolato e Szapiro (2003), a formação de um APL pode ser considerada como uma importante estratégia de competitividade, facilitando a integração e a cooperação entre pequenas e médias empresas aglomeradas em um espaço geograficamente definido, que, neste estudo, trata-se das empresas relacionadas à cadeia de produção do filé de tilápia da região oeste paranaense, que abarca ainda as instituições de ensino, pesquisa e extensão, instituições governamentais e de apoio. A união entre esses agentes favorece a construção de uma rede de conhecimentos e tecnologia que fortalece a competitividade das empresas da cadeia produtiva (SUZIGAN, 1999; CASSIOLATO; SZAPIRO, 2003).

Instituições fomentadoras de crédito

Identificou-se no decorrer da pesquisa, quatro potenciais agentes para a composição do APL da piscicultura do oeste do Paraná, no que tange às instituições fomentadoras de crédito. Entre as possibilidades de apoio financeiro estão as entidades como o Sistema de Cooperativas de Crédito do Brasil - Sicoob, que oferece linhas de crédito e custeio específicas para o setor rural. Na mesma linha, o Cooperativismo de Crédito - Sicredi atua no setor do agronegócio com aporte de recursos para financiamento e custeio aos produtores, considerando os investimentos e levantamento de recursos por parte dos proprietários.

Entre os meios de financiamento que apoiam o setor com a concessão de crédito está o Programa BB Aquicultura e Pesca do Banco do Brasil. Este programa tem como objetivo atender produtores de pequeno, médio e grande porte. São diversas linhas de crédito que se adequam à realidade de cada produtor, desde o atendimento à Agricultura Familiar quanto à Empresarial.

Por fim, outro agente potencial é o Banco Regional do Extremo Sul - BRDE que oferece mecanismos de apoio à pecuária e à agricultura, beneficiando tanto produtores rurais como pessoas físicas e jurídicas, além de cooperativas agropecuárias. Vários projetos podem ser financiados, como a aquisição de equipamentos para diversos segmentos da agricultura. No apoio à indústria, o BRDE realiza investimentos com foco no aumento da capacidade produtiva da região. Entre as linhas de crédito estão as seguintes: a) Inovagro: inovação tecnológica nas propriedades rurais; b) PCA: projetos de construção e ampliação de armazéns; c) Moderagro: atende a diversos setores da produção, como beneficiamento, industrialização; d) FCO Rural: para compra de máquinas e equipamentos agrícolas.

Considerando a necessidade de investimentos para o desenvolvimento e formação do arranjo produtivo local, os resultados da pesquisa apontam que as instituições de crédito desempenham papel fundamental para consolidação do setor.

Segundo Batalha (1997), uma análise em termos de cadeia produtiva agroindustrial permite uma visão global do sistema, evidenciando a importância da articulação entre os agentes econômicos privados, o poder público e as necessidades dos consumidores. Além disso, permite uma melhor coordenação 
entre os agentes envolvidos diretamente com as atividades da cadeia produtiva, bem como as instituições de apoio e agentes governamentais.

Para Storper e Harrison (1991), uma estrutura de coordenação se forma a partir das interações que ocorrem ao longo das cadeias, em que se verificam relações verticais e horizontais entre as firmas, incluindo o ambiente institucional e organizacional e o encadeamento das atividades desde a produção de insumos até a distribuição do produto ao consumidor final.

Nesse aspecto, Souza (2007) destaca que a reorganização das cadeias produtivas, que, neste estudo, pode ser traduzido em uma organização do setor em APL, é movida pela exigência de um mercado competitivo, que representa a sobrevivência das empresas de forma sustentável ao obter maiores vantagens competitivas. Sendo assim, é muito importante o envolvimento dos atores da cadeia produtiva para a reorganização da mesma na concepção de um arranjo produtivo eficiente, inovador e competitivo.

A estrutura analítica apresentada na figura 2, também conhecida como metodologia PENSA de estudos de sistemas agroindustriais, demonstra a organização do setor produtivo em uma composição de quatro etapas: a) descrição do sistema, incluindo a análise da organização industrial de cada segmento que compõe o sistema; b) apresentação das transações típicas entre segmentos do sistema; c) análise institucional inserida no modelo, trazendo as regras e regimentos do sistema e, d) o comportamento das organizações e sua influência sobre os agentes.

Figura 2. Organização da Cadeia Produtiva da Tilapicultura na região oeste do Paraná

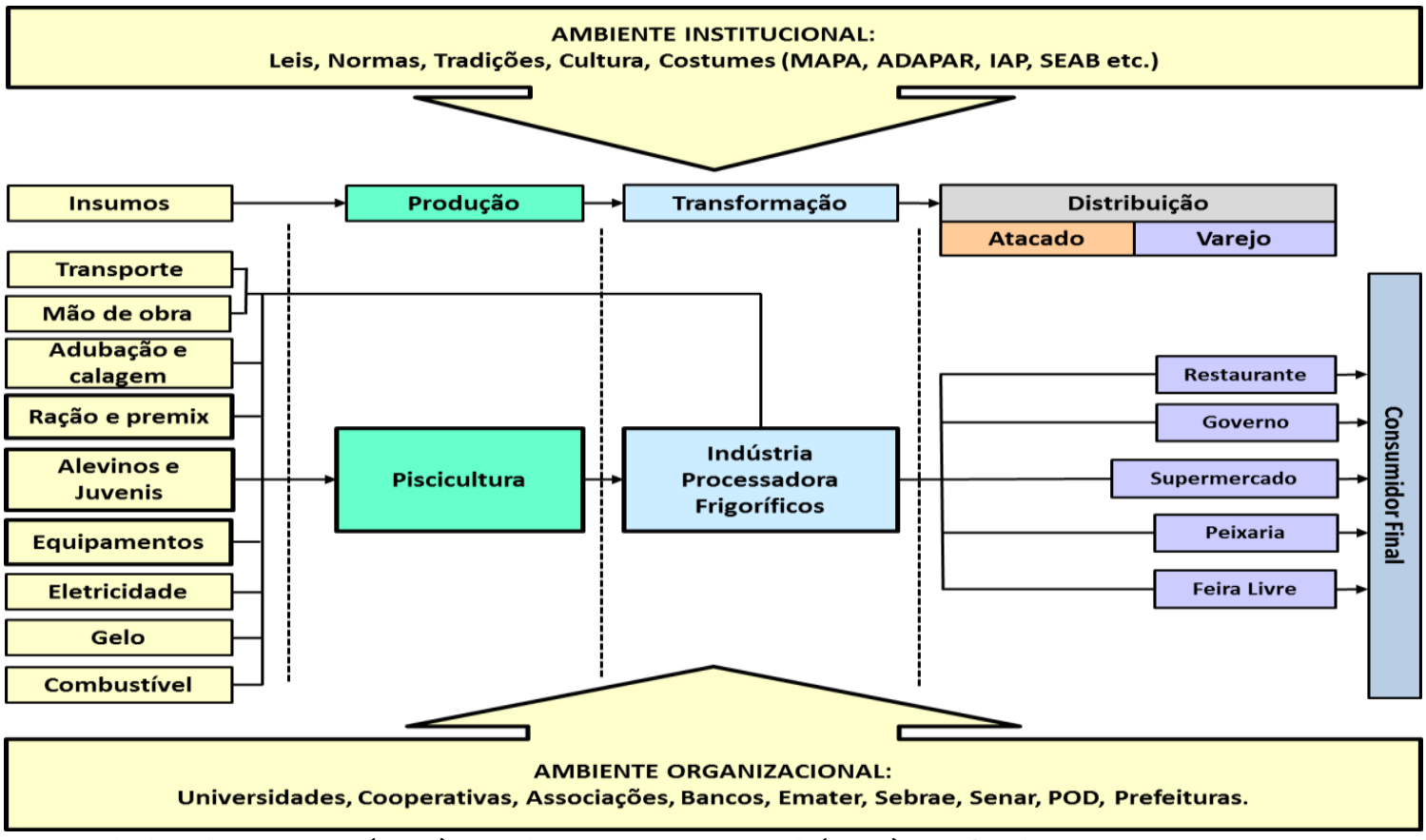

Fonte: dados da Pesquisa (2016) com base em Neves et al. (2014) - Método PENSA.

De acordo com Farina (1999), a capacidade das empresas em alterar a seu favor características do ambiente competitivo, como estrutura de mercado e padrão de concorrência, é de fundamental importância, principalmente nas cadeias produtivas de alimentos, pois ainda subsistem importantes espaços para ações 
A cadeia produtiva da tilápia no oeste do Paraná: uma análise sobre a formação de um arranjo produtivo local

estratégicas, seja na criação de novos mercados, bem como na segmentação dos mercados existentes.

Silva et al. (2005) corroboram a afirmativa ao destacarem que a competitividade da piscicultura depende da capacidade de produtores, poder público e outros atores da cadeia desenvolverem um modelo de produção que valorize as oportunidades oferecidas pelos ambientes físico, econômico e institucional.

De forma complementar, o quadro 2 apresenta os elementos característicos relacionados aos sete elos que compõem a cadeia produtiva, destacando a relevância dos agentes na composição do grupo para um possível formação do APL.

\section{Quadro 2. Elementos característicos dos principais agentes}

\begin{tabular}{|l|l|}
\hline PRINCIPAIS AGENTES DO APL & \multicolumn{1}{|c|}{ ELEMENTOS CARACTERÍSTICOS DOS AGENTES } \\
\hline Indústria de ração e premix. & $\begin{array}{l}\text { Produção de rações e aditivos utilizados na criação dos alevinos e } \\
\text { engorda dos peixes. }\end{array}$ \\
\hline $\begin{array}{l}\text { Empresa de equipamentos } \\
\text { para piscicultura. }\end{array}$ & $\begin{array}{l}\text { Produção e comercialização dos equipamentos utilizados na } \\
\text { produção dos peixes, no transporte e nos frigoríficos de pescado. }\end{array}$ \\
\hline $\begin{array}{l}\text { Setor de criação de alevinos e } \\
\text { engorda de peixes. }\end{array}$ & $\begin{array}{l}\text { Criação dos alevinos que serão engordados para posterior utilização } \\
\text { nos frigoríficos na transformação do peixe em filé. }\end{array}$ \\
\hline $\begin{array}{l}\text { Setor de abate e } \\
\text { processamento de pescado. }\end{array}$ & $\begin{array}{l}\text { Transformaç̃ão da matéria-prima (peixe) em proteína animal } \\
\text { processada (filé de tilápia). }\end{array}$ \\
\hline $\begin{array}{l}\text { Setor de cooperativas e } \\
\text { associações de produtores. }\end{array}$ & $\begin{array}{l}\text { Organização e apoio aos produtores de peixes, criadores de alevinos } \\
\text { e setor de abate e processamento. }\end{array}$ \\
\hline $\begin{array}{l}\text { Setor de Instituições de } \\
\text { ensino, pesquisa e extensão. }\end{array}$ & $\begin{array}{l}\text { Formação da mão de obra especializada e capacitação técnica na } \\
\text { produção, e suporte na evolução dos processos e melhoria da } \\
\text { atividade. }\end{array}$ \\
\hline $\begin{array}{l}\text { Instituições fomentadoras de } \\
\text { crédito }\end{array}$ & $\begin{array}{l}\text { Apoio financeiro no custeio para produção e processamento do } \\
\text { pescado. }\end{array}$ \\
\hline
\end{tabular}

Fonte: elaboração dos autores (2016).

\section{Relacionamentos e Análise das Redes Sociais}

Mediante a caracterização da cadeia produtiva para a formação do APL, foi possível identificar as formas de articulação e relacionamento entre os 24 frigoríficos instalados na região com os demais seis agentes inseridos na rede. $O$ intuito dessa identificação consiste em compreender a rede de relacionamento em dois modos. De um lado, importa conhecer a estrutura em si, levando em consideração fatores como a conectividade e a densidade da rede e, por outro lado, realizar as análises de centralidade que permitem compreender os fluxos de recursos e informações que circulam na rede, além de fatores como concentração e poder.

Conforme apresentado no sociograma 1, é possível observar um notável destaque de algumas instituições na rede, com maior número de conexões em relação aos demais atores, como no caso dos frigoríficos TR02, TR04, TRo8 e TR17 (laços fortes) que efetuam intensamente a troca de informações na rede, bem como interagem com laços fracos, representado pelos Produtores de Insumos (IN01, IN02, IN04), pelo Instituto Ambiental do Paraná (IG03), e também com agentes de Distribuição (DI02) e Bancos (IA04) da região onde o estudo foi 
realizado, que foram apontados como parceiros de negócios em que se exerce a de troca de informações na rede por grande parte dos responsáveis pelos frigoríficos.

\section{Sociograma 1. Densidade de relacionamentos na cadeia de produção}

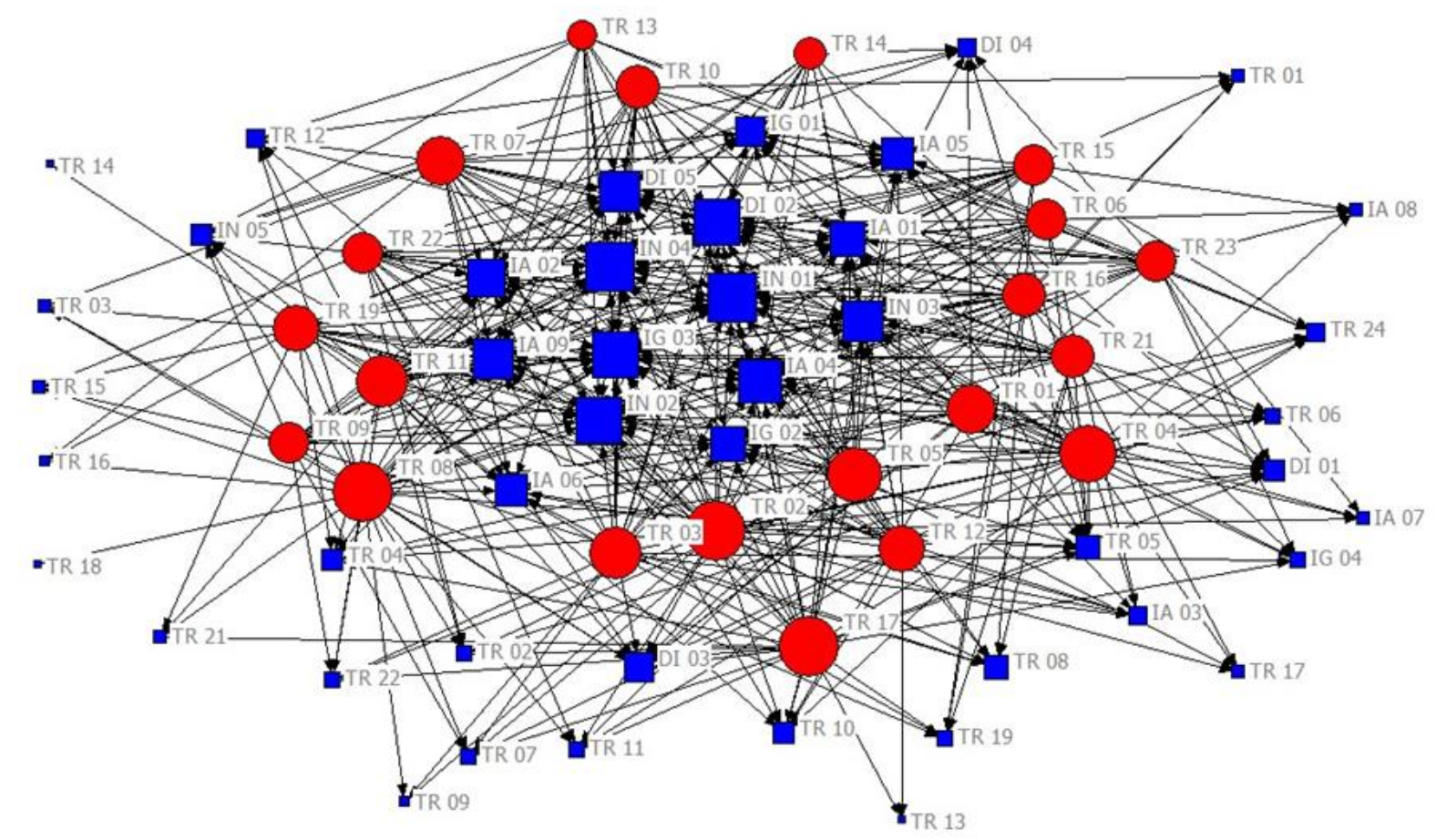

Fonte: dados da Pesquisa (2016).

É importante destacar que as redes são montadas a partir da resposta individual de cada um dos responsáveis pelos frigoríficos analisados, o que envolve suas percepções e interpretações. Dessa forma, é possível que um determinado indivíduo atribua relevância a um determinado relacionamento com outro indivíduo, mesmo que a consideração não seja recíproca.

Uma observação atenta ao sociograma 2 permite relativizar a importância da quantidade de citações recebida por alguns nodos, cuja forma geométrica se destaca em dimensões maiores, como no caso do frigorífico (TR05), que recebeu o maior número de apontamentos de relação, seguido pelo frigorífico (TRo8). 0 destaque do TR05 pode ser atribuído, principalmente, ao fato de adquirir resíduos (carcaças e aparas de peixe) de outros frigoríficos da região para a produção de farinha de peixe (insumo para produção de ração), o que implica em uma ampla troca de informações com este agente. 
A cadeia produtiva da tilápia no oeste do Paraná: uma análise sobre a formação de um arranjo produtivo local

Sociograma 2. Grau de centralidade entre os frigoríficos do Arranjo Produtivo Local

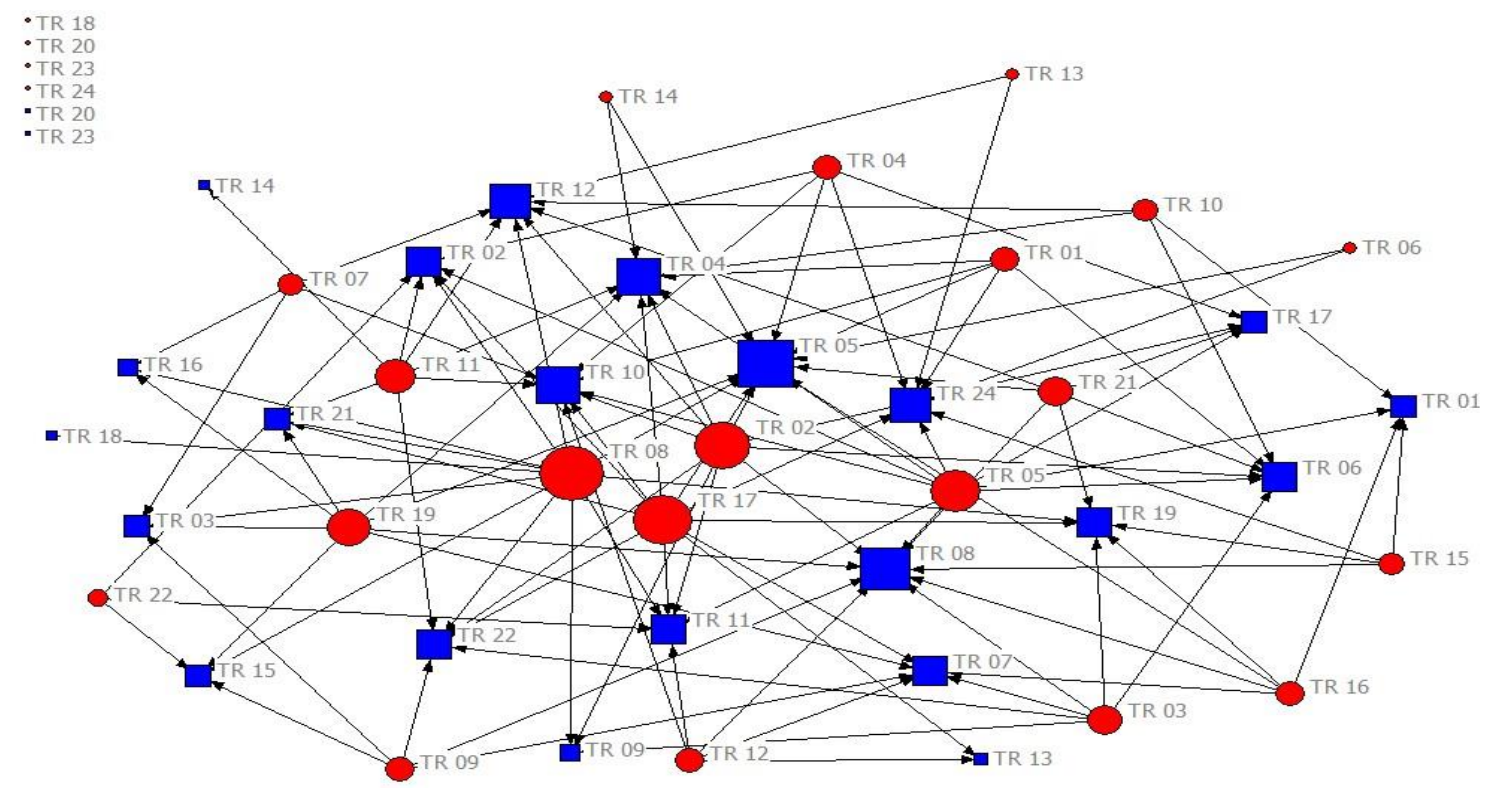

Fonte: dados da Pesquisa (2016).

Em relação ao TRo8, importa ressaltar que o mesmo busca, constantemente, informações junto aos demais frigoríficos, repassa informações, realiza compras conjuntas de matéria-prima (peixe vivo) e insumos, faz ações coletivas para a despesca e transporte de peixes, tem parcerias na venda e distribuição de produtos acabados, entre outras estratégias de ações coletivas. Isso indica a ampla capacidade de diversificação e relacionamento entre os parceiros (Mccarty, 2002).

No quadro 3, apresenta-se com destaque em negrito os três atores com maiores índices de centralidade, pois, ao considerar a posição do nodo, observa-se que os frigoríficos destacados são aqueles que possuem o maior número de apontamentos de relacionamento na rede.

Quadro 3. Nível de centralidade entre os frigoríficos do possível Arranjo Produtivo Local da tilapicultura

\begin{tabular}{|cccc|cccc|}
\hline Frigorífico & Degree & NrmDegree & Share & Frigorífico & Degree & NrmDegree & Share \\
\hline TR 05 & $\mathbf{1 3 . 0 0 0}$ & $\mathbf{5 6 . 5 2 2}$ & $\mathbf{0 . 0 8 0}$ & TR 24 & 7.000 & 30.435 & 0.043 \\
TR 08 & $\mathbf{1 2 . 0 0 0}$ & $\mathbf{5 2 . 1 7 4}$ & $\mathbf{0 . 0 7 4}$ & TR 07 & 7.000 & 30.435 & 0.043 \\
TR 17 & $\mathbf{1 1 . 0 0 0}$ & $\mathbf{4 7 . 8 2 6}$ & $\mathbf{0 . 0 6 8}$ & TR 22 & 7.000 & 30.435 & 0.043 \\
TR 02 & 10.000 & 43.478 & 0.062 & TR 03 & 6.000 & 26.087 & 0.037 \\
TR 11 & 10.000 & 43.478 & 0.062 & TR 15 & 6.000 & 26.087 & 0.037 \\
TR 19 & 9.000 & 39.130 & 0.056 & TR 09 & 6.000 & 26.087 & 0.037 \\
TR 04 & 9.000 & 39.130 & 0.056 & TR 16 & 5.000 & 21.739 & 0.031 \\
TR 10 & 9.000 & 39.130 & 0.056 & TR 14 & 3.000 & 13.043 & 0.019 \\
TR 21 & 7.000 & 30.435 & 0.043 & TR 13 & 3.000 & 13.043 & 0.019 \\
TR 06 & 7.000 & 30.435 & 0.043 & TR 18 & 1.000 & 4.348 & 0.006 \\
TR 12 & 7.000 & 30.435 & 0.043 & TR 20 & 0.000 & 0.000 & 0.000 \\
TR 01 & 7.000 & 30.435 & 0.043 & TR 23 & 0.000 & 0.000 & 0.000 \\
\hline
\end{tabular}

Fonte: dados da Pesquisa (2016). 
É possível observar que os frigoríficos que apresentaram maior grau de centralidade (Degree) foram TR05, TR08 e TR17, seguidos por TR02 e TR11. O grau de centralidade é obtido pela divisão do número de relacionamentos existentes (para cada frigorífico) pelo número de relacionamentos possíveis, que, neste caso, são 23. Dessa forma, o frigorifico TR05 possui o maior índice de centralidade, com um aproveitamento de $56,52 \%$ das oportunidades de relacionamento. Isso significa que, dentre os 23 frigoríficos com os quais poderia ter algum tipo de relação, ele alcança um relacionamento com 13 estabelecimentos, efetuando troca de informações e obtendo um maior nível de conhecimento na rede.

O quadro 4 apresenta as relações da rede sob ótica do grau de proximidade de entrada e saída (OutClosenes e InCloseness) entre os 24 frigoríficos. Essa medida indica a capacidade de um integrante em alcançar os demais elos da rede, calculando as distâncias geodésicas de um ator para se ligar aos demais, o que, de acordo com Camargo e Medina (2016), significa que quanto mais alto os valores de proximidade, maior será esta capacidade, enquanto que os valores menores indicam que os atores não se encontram bem posicionados na rede.

\section{Quadro 4. Grau de proximidade entre os frigoríficos do possível APL da} tilapicultura

\begin{tabular}{|cccc|cccc|}
\hline Frig. & OutClose. & Frig. & InClose. & FRIG. & OutClose. & Frig. & InClose. \\
\hline TR 24 & $\mathbf{2 1 . 6 9 8}$ & TR 08 & $\mathbf{2 9 . 4 8 7}$ & TR 19 & 17.293 & TR 04 & 25.556 \\
TR 18 & $\mathbf{1 9 . 0 0 8}$ & TR 02 & $\mathbf{2 8 . 7 5 0}$ & TR 22 & 17.293 & TR 22 & 25.000 \\
TR 08 & $\mathbf{1 8 . 4 0 0}$ & TR 17 & $\mathbf{2 8 . 7 5 0}$ & TR 09 & 16.912 & TR 07 & $\mathbf{2 4 . 7 3 1}$ \\
TR 05 & $\mathbf{1 8 . 4 0 0}$ & TR 05 & $\mathbf{2 8 . 3 9 5}$ & TR 21 & 16.912 & TR 10 & $\mathbf{2 4 . 2 1 1}$ \\
TR 10 & 18.254 & TR 19 & $\mathbf{2 7 . 3 8 1}$ & TR 17 & 16.788 & TR 01 & $\mathbf{2 3 . 9 5 8}$ \\
TR 04 & 17.969 & TR 21 & 27.059 & TR 15 & 16.788 & TR 14 & 23.232 \\
TR 11 & 17.969 & TR 11 & 26.744 & TR 03 & 16.667 & TR 06 & $\mathbf{2 3 . 0 0 0}$ \\
TR 06 & 17.829 & TR 12 & 26.744 & TR 16 & 16.547 & TR 13 & 22.115 \\
TR 12 & 17.829 & TR 16 & 26.437 & TR 13 & 16.312 & TR 24 & 4.670 \\
TR 02 & 17.692 & TR 03 & $\mathbf{2 6 . 1 3 6}$ & TR 14 & 15.862 & TR 18 & 4.167 \\
TR 01 & 17.424 & TR 09 & 25.843 & TR 20 & $\mathbf{4 . 1 6 7}$ & TR 20 & $\mathbf{4 . 1 6 7}$ \\
TR 07 & 17.424 & TR 15 & $\mathbf{2 5 . 8 4 3}$ & TR 23 & $\mathbf{4 . 1 6 7}$ & TR 23 & $\mathbf{4 . 1 6 7}$ \\
\hline
\end{tabular}

Fonte: dados da Pesquisa (2016).

Dessa forma, observa-se, no quadro 4, um destaque para atores como o TR24 e TR18 que, anteriormente, não haviam se destacado nas relações da rede, mas se destacam nesta análise com elevado grau de proximidade, dada a grande capacidade destes atores em alcançar os demais elos da rede. Destarte, é importante ressaltar que os atores TR02, TR05, TRo8 e TR17, já mencionados em análises anteriores, figuram entre os quatro mais bem posicionados na rede, tanto para a entrada como para a saída das relações. Porém, o quadro também apresenta os atores TR2o e TR23, sem muito destaque, aparecendo como nós soltos na rede, ou seja, distantes dos demais ao se tratar das relações de proximidade.

$\mathrm{Na}$ tabela 2 a seguir, são apresentados os indicadores gerais de toda a rede, considerando os 24 frigoríficos. Conforme se observa, o que teve maior número de apontamentos em relação à troca de informações, serviços ou ações conjuntas, foi 
mencionado por 13 vezes, sendo este o maior número de apontamentos (maximum). Isso significa que dentre as 24 unidades, uma delas (TR05) manteve relações com outras 13 . Além disso, indica também que nenhuma delas alcança a rede completamente. Por outro lado, há representantes que não foram apontados por nenhum outro frigorífico, ou seja, não se relaciona na rede. O número médio (mean) de relações na rede é de 6,75, com um desvio padrão (Std. Dev.) de 3,406. A tabela 02 demonstra ainda a soma de todas as relações existentes na rede, que neste caso, é de 162 relações dentre as 552 possíveis ( $24 \times 23$ ), o que representa um percentual de $29,34 \%$ de densidade de relacionamento. Isso demonstra a alta conectividade entre os atores e o quanto a rede está interligada, facilitando o fluxo entre os elos de modo mais igualitário.

Tabela 2. Saída de estatística descritiva do programa Ucinet

\begin{tabular}{llccc}
\hline & & Degree & NrmDegree & Share \\
\hline 1 & Mean & 6,750 & 29,348 & 0,042 \\
2 & Std Dev & 3,406 & 14,811 & 0,021 \\
3 & Sum & 162,000 & 704,348 & 1,000 \\
4 & Variance & 11,604 & 219,360 & 0,000 \\
5 & SSQ & 1372,000 & 25935,729 & 0,052 \\
6 & MCSSQ & 278,500 & 5264,650 & 0,011 \\
7 & Euc Norm & 37,041 & 161,046 & 0,229 \\
8 & Minimum & 0,000 & 0,000 & 0,000 \\
9 & Maximum & 13,000 & 56,522 & 0,000 \\
10 & N of Obs & 24,000 & 24,000 & 24,000 \\
\hline \multicolumn{5}{l}{ Network Centralization $=29,64 \%$} \\
\multicolumn{4}{l}{ Blau Heterogeneity $=5,23 \%$ - Normalized $(I Q V)=1,11 \%$} & \\
\hline
\end{tabular}

Fonte: dados da pesquisa (2016).

Embora existam alguns atores centrais, a capacidade da rede em centralizar as intermediações entre os nós é de $29,64 \%$. Isso significa que as informações que circulam na rede não ficam concentradas em um número muito pequeno e nem muito grande de atores, ou seja, existe uma concentração intermediária de atores que possuem as informações e as disseminam na rede, o que pode ser interessante sob o aspecto de liderança e formação da estrutura de governança da rede, pois possibilita que um ator realize a intermediação das comunicações entre pares de nós. Estes nós são também conhecidos como "atores-ponte".

Esse resultado corrobora com os percentuais encontrados por Perrow (1992) em revisão de literatura de redes horizontais de Micro, Pequenas e Médias Empresas - MPMEs que aponta haver pouca diferença entre o porte, o poder e a posição estratégica das firmas. Da mesma forma, Alves (2013) destaca que, ao analisar governança e inovação em APL de bolsas e calçados, encontrou um índice de centralização de $11,32 \%$, o que destaca a existência de poucos atores centrais.

\section{Estrutura de Governança para o Arranjo Produtivo Local}

A capacidade de comandar as relações entre as organizações, ou seja, a governança da atividade produtiva deve ser considerada como fator de extrema importância na constituição de APLs, devendo os atores que compõem a cadeia indicar o representante que melhor se destaca para o exercício desta função. $O$ 
interesse de coordenação também pode partir de lideranças políticas ou instituições de apoio, com capacidade de concentrar esforços de liderança e promover as ações necessárias para a geração de vantagens competitivas por meio da economia de aglomerações, tornando-as factíveis e sustentáveis.

Embora o Programa Oeste em Desenvolvimento (IA08) tenha sido pouco apontado em termos de relação pelos representantes dos frigoríficos visitados, ele se apresenta como um dos atores-chave com potencial para a governança da atividade, pois atua fortemente na região sob os incentivos do PTI desenvolvendo ações de governança regional por meio de um processo participativo e fomentando, no território, a cooperação entre os atores, públicos e privados, para o planejamento e implementação de estratégias de desenvolvimento integradas. Entretanto, seria necessário um maior envolvimento deste agente, com a ampla rede de atores que se forma na cadeia produtiva, incluindo-os no fórum de relacionamento da câmara técnica de peixe.

Ressalta-se que entre as instituições de apoio ligadas ao ambiente organizacional, que poderiam ser responsáveis pelas articulações (associações, cooperativas, Programa Oeste em Desenvolvimento, Emater), bem como aquelas que poderiam realizar ações voltadas para a inovação (Universidades, Sebrae), não assumem um papel de destaque quanto aos critérios de centralidade, proximidade e intermediação na rede. As prefeituras (IA09) até se destacam na rede, por haver um significativo grau de relacionamento. Entretanto, os resultados da pesquisa apontam que tais relacionamentos estão mais voltados para a fiscalização dos frigoríficos, ou seja, suas ações estão mais direcionadas ao ambiente institucional do que organizacional. Pelo exposto, entende-se que as práticas de inovação das empresas, tanto para o desenvolvimento quanto para a difusão tecnológica, sofrem maior influência das relações diretas entre os próprios frigoríficos (laços fortes) do que influências de outras organizações de referência no mercado ou instituições de apoio (laços fracos).

Ademais, os atores da cadeia produtiva sentem a necessidade de uma maior aproximação com os elos de apoio e, desta forma, acredita-se que o Programa Oeste em Desenvolvimento, que já vem realizando ações no sentido de contribuir para a coordenação e fortalecimento da cadeia produtiva do peixe na região oeste do Paraná, poderia obter maior êxito no seu objetivo, que consiste em promover o desenvolvimento econômico do oeste do Paraná por meio da sinergia das instituições e integração de iniciativas, projetos e ações, ao estreitar o seu relacionamento com os 24 estabelecimentos de processamento de pescado atuantes na região. Isso poderia fortalecer, ainda mais, as atividades de integração social que a entidade vem desenvolvendo na região, assim como fomentar a possibilidade de implantação do APL da tilapicultura do oeste paranaense.

\section{CONSIDERAÇÕES FINAIS}

Com base nos critérios elencados para uma possível implantação do APL de tilapicultura no oeste paranaense, os resultados apontam a existência de uma relevante concentração da estrutura produtiva e de agentes com potencialidade para a coordenação das ações coletivas. Além disso, indica a existência de uma importante rede de relacionamentos e de cooperação entre os principais elos e atores da cadeia de produção. Esse cenário revela o grande potencial para 
efetivamente se consolidar o APL na região, considerabdo a notável importância da contribuição das instituições de apoio, tanto organizacional quanto institucional, na construção deste espaço de desenvolvimento social, econômico e regional.

A formação do APL pode exercer forte influência na economia local e regional, pois uma das principais contribuições que o APL da tilapicultura na região oeste do Paraná pode proporcionar consiste, basicamente, na organização setorial e no aproveitamento de sinergias criadas pelas próprias entidades envolvidas, bem como na geração de externalidades positivas benéficas a toda comunidade regional e de seu entorno. Além disso, possibilita o aproveitamento dos benefícios resultantes da constante troca de informações e de conhecimentos entre todos os agentes engajados, gerando inovação e criatividade aos envolvidos. Com a inovação, consequentemente, obtém-se o desenvolvimento de novas técnicas de produção, redução de custos, estreitamento de laços e relacionamento com fornecedores, prestadores de serviços e mercado consumidor. Outro benefício que se observa, consiste no fato de que, por intermédio do arranjo produtivo, a somatória das ações entre as partes é maior que a somatória das ações individuais, o que proporciona o crescimento das empresas ao gerar mais postos de trabalho, maior renda, maior acesso a mercados, principalmente o internacional, considerado atingível apenas para as grandes empresas que já atuam na exportação de carne de aves e suínos na região.

Ademais, a formação do APL da tilapicultura pode contribuir significativamente para uma maior diversificação econômica da região que, atualmente, apresenta-se como referência na avicultura e suinocultura. Dessa forma, a produção da carne de peixe pode contribuir para a consolidação do setor de proteína animal e, assim, aproveitar as diversas sinergias advindas deste setor, que já é destaque mundial na região de estudo.

\section{REFERÊNCIAS}

ALMEIDA FILHO, N. Apresentação sobre redes. In: TEIXEIRA, F. Gestão de redes de cooperação interempresariais: em busca de novos espaços para o aprendizado e a inovação. Salvador: Casa da Qualidade, 2005.

ALVES, S. T. DE J. Governança e inovação em rede de APL: estudo de caso de bolsas e calçados. 2013. Dissertação (mestrado em Administração). Universidade Federal de Minas Gerais. Belo Horizonte, 2013.

AMATO NETO, J. Redes de cooperação produtiva e clusters regionais:

oportunidades para as pequenas e médias empresas. São Paulo: Atlas, 2000.

BATALHA, M. O. (Coord). Gestão Agroindustrial. Editora Atlas. v. 1, São Paulo. 1997.

BRASIL. Ministério da Pesca e Aquicultura. Boletim Estatístico da Pesca e Aquicultura 2011. Versão preliminar. Disponível em:

http://www.mpa.gov.br/index.php/informacoes-e-estatisticas/estatistica-da-pesca-eaquicultura. Acesso em: 13 abr. 2014. 
BRASIL. Ministério da Pesca e Aquicultura. Censo Aquícola Nacional de 2008. Uso de referências e documentos eletrônicos. Disponível em:

http://www.mpa.gov.br/images/Docs/Informacoes_e_Estatisticas/Censo_maio20132.pdf. Acesso em: 14 maio 2011.

CANTNER, U.; GRAF, H. Innovation Networks: formation, performance and dynamics. In: Antonelli, C. (org.). Handbook on the economic complexity of technological change. Cheltenham: Edward Elgar, 2011.

CAMARGO R. S.; MEDINA, G. O efeito do programa territorial nas relações sociais dos agricultores familiares do território da cidadania do Vale do Rio Vermelho, em Goiás, Brasil. Interações, v.17, n.1, p.54-65, 2016.

CAMPOS, A. C.; CALLEFI, P. Arranjos Produtivos Locais de confecção no Paraná: uma análise comparativa. Informe GEPEC, Toledo, v. 13, n. 2, p. 85-103, jul./dez. 2009.

Disponível em:

<e-revista.unioeste.br/index.php/gepec/article/download/2351/2695?>.

CARDOSO, U. C.; CARNEIRO, V. L. N.; RODRIGUES, E. R. Q. APL: Arranjo Produtivo Local. Sebrae: Brasília, 2014.

CASSIOLATO, J. E.; SZAPIRO, M. Uma caracterização de arranjos produtivos locais de micro e pequenas empresas. In: LASTRES, H. M. M.; CASSIOLATO, J. E.; MACIEL, M. L. Pequena Empresa: cooperação e desenvolvimento local. Rio de Janeiro, Relume Dumará, 2003. p. 35-50.

FARINA, E. M. M. Q. Competitividade e coordenação de sistemas agroindustriais: um ensaio conceitual. Revista Gestão e Produção, v.6, n.3, p. 147-161, 1999.

GIL, A. C. Como elaborar projetos de pesquisa. $4^{\text {a }}$ ed. São Paulo: Atlas, 2002.

GRAÇA, C. A. Governança e inovação tecnológica em APLs: um estudo de caso no APL Calçadista de Birigui/SP (anos 1990-2000). 2007. Tese (doutorado em Engenharia de Produção). Universidade de São Paulo. São Paulo, 2007.

GRANDORI, A.; SODA, G. Inter-firm networks: antecedents, mechanisms and forms. Organization studies, v. 16, n. 2, p. 183-214, 1995.

GRANOVETTER, M. The strength of weak ties. The American Journal of Sociology, Chicago, v. 78, n. 6, p. 1360-1380, may. 1973.

HANNEMAN, R. A.; RIDDLE, M. Introduction to social network methods. Riverside, CA: University of California, Riverside, 2005 (published in digital form at http://faculty.ucr.edu/ hanneman/).

IBGE - Instituto Brasileiro de Geografia e Estatística. Produção da Pecuária Municipal; Rio de Janeiro; v.42, 2014. 
A cadeia produtiva da tilápia no oeste do Paraná: uma análise sobre a formação de um arranjo produtivo local

KIM, Y.; CHOI, T. Y.; YAN, T.; DOOLEY, K. Structural investigation of supply networks: a social network analysis approach. Journal of Operations Management, v. 29, p 194-211, 2011.

KNOKE, D.; YANG, S. Social Network Analysis. London: Sage Publications, 2008.

LASTRES, H. M. M.; CASSIOLATO, J. E. (Coord.). Glossário de arranjos e sistemas produtivos e inovativos locais, REDESIST. Rio de Janeiro, 2003. Disponível em: $<w w w . r e d e s i s t . i e . u f r j . b r>$. Acesso em 08 de março de 2016.

LAZZARINI, S. G. Empresas em rede. São Paulo: Cengage Learning, 2008. 86 p.

LEMOS, C. Inovação na era do conhecimento. In: LASTRES, H. M. M. e ALBAGLI, S. (org.). Informação e globalização na era do conhecimento. São Paulo: Campus, 1999. p. 122-144.

MCCARTY, C. Measuring Structure in Personal Networks. Journal of Social Structure 3:1. 2002. Disponível em:

https://www.cmu.edu/joss/content/articles/volume3/McCarty.html. Acesso em: 18 dez. 2016.

NEVES, M. F.; ROSSI, R. M.; LOPES, F. F.; CASTRO, L. T.; MARINO, M. K. Caracterização e quantificação de sistemas agroindustriais visando ações coletivas: um modelo metodológico. SOBER. XLII Congresso Brasileiro de Economia e Sociologia Rural: Dinâmicas Setoriais e Desenvolvimento Regional. Anais...CuiabáMT, 25-28 de julho de 2014.

OLIVEIRA, N.; SOUZA, D. L.; CASTRO, C. C. Análise sociométrica da rede de relacionamento das bibliotecas que constituem o Consórcio das Universidades Federais do Sul-Sudeste de Minas Gerais. Revista Perspectivas em Ciência da Informação, v.19, n.1, p.130-148, 2014.

PARANÁ - Secretaria da Agricultura e Abastecimento - SEAB/PR - 2016; Uso de referências e documentos eletrônicos; Disponível em:

http://www.agricultura.pr.gov.br/modules/noticias/article.php?storyid=5856; Acesso em: 20 de setembro de 2016.

PARANÁ - Secretaria de Estado de Governo - Sistema Estadual de Legislação; Lei n ${ }^{\circ}$ 10.799 de 24 de maio de 1.994: Uso de referências e documentos eletrônicos. Disponível em:

http://www.legislacao.pr.gov.br/legislacao/pesquisarAto.do?action=exibir\&codAto= 6024\&indice=1\&totalRegistros=1. Acesso em: 25 abr. 2016.

PERROW, C. Complex organizations: a critical essay. Glenview, IL: Scott. Foresman, $270 p .1992$.

REDESIST. Glossário sobre arranjos e sistemas produtivos e inovativos locais. Rio de Janeiro, 2003. Disponível em: www.redesist.ie.ufrj.br. Acesso em: 20 abr. 2016. 
RIBEIRO, E. M. B. A.; BASTOS, A. V. B. Redes sociais interorganizacionais na efetivação de projetos sociais. Psicol Soc., v. 23, p. 282-292, 2011.

ROSA, E. A rede de inovação no cluster de biotecnologia de Belo Horizonte: um estudo sobre interações sociais, ambiente e a capacidade tecnológica das empresas. 2004. 158f. Dissertação (Mestrado em Ciências Sociais). Belo Horizonte: Pontifícia Universidade Católica de Minas Gerais, 2004.

SILVA. N. J. R.; BEURET, J. E.; MIKOLASEK, O. FONTENELLE, G.; DABBADIE, L.; MARTINS, M. I. E. G. Dinâmicas de desenvolvimento da piscicultura e políticas públicas no Vale do Ribeira, Estado de São Paulo. Cadernos de Ciência e Tecnologia, Brasília, v. 22, n. 1, p. 139-151, jan./abr. 2005.

SINDIRAÇÕES. Sindicato Nacional da Indústria de Alimentação Animal. Boletim Informativo do setor, 2016. Disponível em:

<file://D:/DESKETOP/boletim_informativo_do_setor_maio_2016_vs_final_port.pdf.> Acesso em: 22/09/2016

SOUZA, M. P. de. Governança da Cadeia Produtiva Agroindustrial do Leite de Rondônia. In: BRASIL, W. Desenvolvimento Regional e Meio Ambiente, 2007, Cap. 7, pag.: 134 a 164.

STORPER, M.; HARRISON, B. Flexibility, hierarchy and regional developments: the changing structure of industrial production systems and their forms of governance in the 1990. Research Policy. North-Holland, v. 20, n. 5. 1991.

SUZIGAN, W. (Org.). Clusters e sistemas locais de inovação. Anais do seminário internacional, Campinas: UNICAMP, 1999.

SUZIGAN, W.; GARCIA, R.; FURTADO, J. Estruturas de governança em arranjos ou sistemas locais de produção. Gestão \& Produção, São Carlos, v. 14, n. 2, p. 425-439, 2007.

TOMAÉL, M. I.; MARTELETO, R. M. Redes Sociais: posições dos atores no fluxo da informação. Revista Eletrônica de Biblioteconomia e Ciência da Informação, Florianópolis, n. esp. p. 75-91, 2006.

TOMAEL, M. I.; MARTELETO, R. M. Redes sociais de dois modos: aspectos conceituais. Transinformação, v. 25, n. 3, p. 245-253, 2013. 
A cadeia produtiva da tilápia no oeste do Paraná: uma análise sobre a formação de um arranjo produtivo local

Aldi Feiden. Doutor em Ecologia de Ambientes Aquáticos Continentais. Graduado em Agronomia pela Universidade Estadual de Maringá, UEM, Brasil. aldifeiden@gmail.com

Manoel João Ramos. Mestre em Desenvolvimento Regional e Agronegócio pela Unioeste. Engenheiro de Produção Agroindustrial pela PUC-PR. eng.major@hotmail.com

Antonio Carlos Chidichima. Universidade Estadual do Oeste do Paraná.Mestre em Desenvolvimento Rural Sustentável. Graduado em Tecnologia de Administração de Pequenas e Médias Empresas pela Unopar-PR. prof.chidichima@gmail.com

Carla Maria Schmidt. Doutora em Administração. Graduada em Secretariado Executivo Bilingüe pela Universidade Estadual do Oeste do Paraná, UNIOESTE, Brasil. carlamariaschmidt@hotmail.com

Mônica Lady Fiorese. Doutora em Engenharia Química. Graduada em Engenharia Química. Fundação Universidade Regional de Blumenau, FURB, Brasil. mlfiorese@gmail.com

Anderson Coldebella. Mestre em Engenharia Agrícola. Graduado em Engenharia de Pesca. Universidade Estadual do Oeste do Paraná, UNIOESTE, Brasil. anderson.coldebella@ifpr.edu.br 